they have for biochemistry. Moreover, for them, the bibliography of more than fifty pages is quite unrealistic-a few selected references to reviews would be much less daunting. It was disappointing not to find any mention of the development of British antilewisite. Perhaps this was modesty on the part of one of the authors (R. H. S. T.), who was associated with this fine piece of war-time research of the Oxford School of Biochemistry; but the work is still of great interest, and it affords an exeellent example of fundamental biochemical research which has led to valuable practical advances in medical treatment. Perhaps it might be included in future editions.

D. C. Harrison

\section{CARDIAC NECROSES}

The Chemical Prevention of Cardiac Necroses By Prof. Hans Selye. Pp. $x+235$. (New York: The Ronald Press Company, 1958.) 7.50 dollars.

$T$

HIS extraordinary monograph reports work done by an anonymous team of investigators (acknow ledgments are confined to secretarial staff) following the discovery in 1957 that a cardiomyopathy with necroses could be induced in rats by the administration of cortico-steroids and certain electrolytes; this condition was called "electrolyte-steroid-cardiopathy with necroses", but abbreviated to E.S.C.N.

It had been known for some 14 years beforehand that steroids administered with sodium chloride could induce a hyalinizing myocarditis (without necrosis) associated with periarteritis nodosa and nephrosclerosis. The new discovery excited interest because of the prominence of myocardial necrosis and the lack of the associated lesions just mentioned. The nature of this new lesion suggested to Prof. Selye a possible relationship with myocardial necrosis induced by other means, such as potassium deficiency, administration of digitalis or vitamin $D$ sterols, in experimental animals and occurring for reasons unknown in man.

The experiments reported here show that steroids with both gluco-and mineralo-corticoid activity are necessary for the production of this condition. Sodium chloride has no effect on its development, unless the animals are also subjected to 'stress', but sodium phosphate, sulphate, or perchlorate will induce it in the animal previously treated with steroids. Other electrolytes, it appears, have a protective quality when administered simultaneously ; the most potent of these are potassium and magnesium chloride.

The bulk of the book is devoted to reporting these experiments giving the detailed results of the innumerable permutations of steroids, electrolytes, both aggravating and protective, and various unpleasant sounding forms of 'stress' applied to series of rats. The rest of the book is given to an introductory review of the historical background and to discussion of the possible hypotheses applicable to the observed results. There is finally a prophetic chapter discussing the future significance of these results in relation to the possible use of simple electrolytes to prevent myocardial necrosis in man.

The experimental study was certainly ambitious and thorough, but in some respects seems to have been over-elaborated. Prof. Selye sees great relevance in his observations on rats to certain naturally occurring conditions in man, but it is difficult to accept this. The discussion which deals with this aspect of the work and which, perhaps not surprisingly, rejects other hypotheses in favour of regarding the necrotizing cardiopathies "As 'Diseases of Adaptation' caused by some derailment of the General Adaptation Syndrome" lacks conviction and is often specious.

The following passage seems characteristic of the book: "Since the discovery of the E.S.C.N. less than a year ago, more than 30,000 rats were used in this Institute for experiments designed to clarify certain aspects of this subject. It is evident that the complete evaluation of this enormous mass of material poses almost insuperable problems and many of our present hypotheses will undoubtedly have to be abandoned in the light of future research". One wonders if the death of the 30,000 was worth while.

\section{C. Deuchar}

\section{WATER RESOURCES}

\section{Ground Water Hydrology}

By Prof. David Keith Todd. Pp. xii +336 . (New York : John Wiley and Sons, Inc.; London: Chapman and Hall, Ltd., 1959.) 86s. net.

$\mathrm{T}$ $\mathrm{HE}$ increased demand for water in recent years, in the form of major water supply and irrigation schemes in all parts of the world, has accentuated the importance of the assessment and development of ground-water resources. This trend is by no means confined to under-developed countries. In England and Wales, for example, the estimated demand for water in 1965 is one and a quarter times that of 1955 . In this sense, Prof. Todd's book is timely. Too long has ground-water been considered in a woolly, qualitative fashion by engineer and geologist. The need is for a quantitative assessment of ground-water resources and development potential. The recent application of the radioactive decay of tritium to the time dating of water is undoubtedly the key to quantitative work and marks the beginning of what may be a fruitful period of study.

This readable and well-presented text is addressed to a wide group-"students, specialists in hydraulics, geologists..." and is a comprehensive account of fundamentals, methods and problems in the field of ground-water hydrology. The reader is led very logically through the geology of occurrence of ground water to the equations of seepage and flow into wells. While the subject-matter is familiar, the presentation is fresh and clear. It is inevitable that pure American practice is presented at times, as in the chapters on the construction of wells and the legal aspects of ground-water, but this is more than balanced by the American contributions in the form of "Basin Wide" development and artificial re-charge, for which work Prof. Todd is best known in Europe. Both these topies are new to text-books and they make a significant contribution to the value of the book.

The extent to which ground-water technology is indebted to the petroleum industry is shown by the two chapters on surface and sub-surface investigation techniques. Highly developed resistivity, seismic and magnetic methods are benefits derived from this wealthy relation.

The text is supported by well-chosen American data and an impressive array of some seven hundred references.
E. Militer 